Article

\title{
Different Sensitivity of Control and MICU1- and MICU2-Ablated Trypanosoma cruzi Mitochondrial Calcium Uniporter Complex to Ruthenium-Based Inhibitors
}

\author{
Mayara S. Bertolini and Roberto Docampo *(C) \\ Center for Tropical and Emerging Global Diseases and Department of Cellular Biology, University of Georgia, \\ Athens, GA 30606, USA; maybertolini@uga.edu \\ * Correspondence: rdocampo@uga.edu; Tel.: +1-706-542-8104
}

Received: 29 October 2020; Accepted: 5 December 2020; Published: 7 December 2020

check for updates

\begin{abstract}
The mitochondrial $\mathrm{Ca}^{2+}$ uptake in trypanosomatids shares biochemical characteristics with that of animals. However, the composition of the mitochondrial $\mathrm{Ca}^{2+}$ uniporter complex (MCUC) in these parasites is quite peculiar, suggesting lineage-specific adaptations. In this work, we compared the inhibitory activity of ruthenium red (RuRed) and Ru360, the most commonly used MCUC inhibitors, with that of the recently described inhibitor Ru265, on Trypanosoma cruzi, the agent of Chagas disease. Ru265 was more potent than Ru360 and RuRed in inhibiting mitochondrial $\mathrm{Ca}^{2+}$ transport in permeabilized cells. When dose-response effects were investigated, an increase in sensitivity for Ru360 and Ru265 was observed in TcMICU1-KO and TcMICU2-KO cells as compared with control cells. In the presence of RuRed, a significant increase in sensitivity was observed only in TcMICU2-KO cells. However, application of Ru265 to intact cells did not affect growth and respiration of epimastigotes, mitochondrial $\mathrm{Ca}^{2+}$ uptake in Rhod-2-labeled intact cells, or attachment to host cells and infection by trypomastigotes, suggesting a low permeability for this compound in trypanosomes.
\end{abstract}

Keywords: calcium; mitochondrial calcium uniporter; ruthenium red; Trypanosoma cruzi

\section{Introduction}

The mitochondria have a fundamental role in intracellular $\mathrm{Ca}^{2+}$ homeostasis, buffering cytosolic $\mathrm{Ca}^{2+}$ increases arising from both influx from the extracellular space and release from intracellular organelles. $\mathrm{Ca}^{2+}$ is taken up by a channel known as mitochondrial $\mathrm{Ca}^{2+}$ uniporter (MCU), and once inside, it stimulates several dehydrogenases [1,2] and the ATP synthase [3,4] to generate ATP. The MCU was found almost sixty years ago in kidney mitochondria $[5,6]$, but its molecular identity was discovered more recently $[7,8]$. The discovery that Trypanosoma cruzi, the agent of Chagas disease, possesses a mitochondrial $\mathrm{Ca}^{2+}$ uptake mechanism with similar characteristics to those of animal mitochondria $[9,10]$, combined with the finding of the absence of the channel in Saccharomyces cerevisiae [11] and the availability of the genomes of these species, was important for the molecular identification, first of a modulator of the channel, mitochondrial $\mathrm{Ca}^{2+}$ uptake 1 (MICU1) [12] and then of the pore subunit of the channel or MCU $[7,8]$. After this discovery several accessory proteins were found, like MCU regulator 1 (MCUR1) [13], MICU2 and MICU3 [14], MCUb [15], and essential MCU regulator (EMRE) [16], comprising an MCU complex (uniplex or holocomplex). T. cruzi MCU complex, however, does not possess the MCUR1, MICU3 or EMRE components of the animal uniporter and, in contrast, possesses four $\mathrm{Ca}^{2+}$-conducting subunits: MCU, MCUb, MCUc, and MCUd [17]. Two of these subunits, MCUc and MCUd, are only present in trypanosomatids $[17,18]$. These four subunits form hetero-oligomers, probably hetero-hexamers [18]. Trypanosomatid MCU complexes 
also differ from those of animals in that the MCUb subunit is a $\mathrm{Ca}^{2+}$-conducting subunit and does not have a dominant-negative activity on the MCU complex [18,19]. In addition, trypanosomes MICU1 and MICU2 do not form dimers linked by disulfide bonds and do not have individual gatekeeping activity preventing $\mathrm{Ca}^{2+}$ influx through the uniporter at low $\mathrm{Ca}^{2+}$ concentrations [20], as the animal proteins have [21-23]. All these characteristics are suggestive of the parallel evolution of the complex in trypanosomes [24], which belong to the Discoba supergroup of eukaryotes, and animal cells, which belong to the Opisthokonta supergroup.

Early work demonstrated the inhibition of mitochondrial $\mathrm{Ca}^{2+}$ uptake in $\mathrm{T}$. cruzi by ruthenium red (RuRed) [10]. However, Ru360, which is the most commonly used MCU inhibitor in animal cells, was never tested on trypanosomes. Ru360 is a binuclear oxo-bridged ruthenium ammine complex that has high absorbance at $360 \mathrm{~nm}$ [25]. Site-directed mutagenesis of the S259 residue near the pore motif (DIME) of human MCU to alanine resulted in partial resistance to Ru360 inhibition, suggesting that this amino acid is important for the inhibition [8]. Interestingly, all the T. cruzi monomers of the MCU complex lack this serine residue [17]. Other work was consistent with the binding of RuRed/Ru360 with the aspartate(D)-ring of MCU's selectivity filter [26,27], which is within the second transmembrane domain of the MCU monomer [28] and is solvent-exposed in contrast to the glutamate(E)-ring located deeper in the pore. It was also found that MICU1 suppresses the inhibition of MCU by RuRed/Ru360, which binds to the DIME motif of MCU through a DIME-interacting domain (DID) [29]. Given that the T. cruzi mitochondrial uniporter differs extensively from the animal uniporter, we explored whether ruthenium derivatives are able to inhibit $\mathrm{Ca}^{2+}$ transport in T. cruzi and whether MICU1 or MICU2 suppresses MCU inhibition by these compounds.

In this work, we report the inhibitory activity of RuRed as compared to Ru360 and the recently described cell-permeable inhibitor Ru265 [30] on mitochondrial $\mathrm{Ca}^{2+}$ uptake in T. cruzi. We show that Ru265 is the most effective inhibitor and that this inhibition is increased in TcMICU1- and TcMICU2-knockout cells. The use of Ru265 in intact cells did not result in phenotypic changes suggesting low permeability of this compound in trypanosomes.

\section{Results}

\subsection{Inhibition of Mitochondrial $\mathrm{Ca}^{2+}$ Uptake by Ruthenium-Based Compounds}

We first tested the effect of different concentrations of inhibitors on $\mathrm{Ca}^{2+}$ uptake, as measured by the change in fluorescence of calcium green 5-N, by digitonin-permeabilized control and TcMICU1-KO and TCMICU2-KO epimastigotes. These $\mathrm{KO}$ cells were obtained by the CRISPR/Cas9 method in previous work [20], and we used cells transfected with a scrambled sgRNA as control. Figure 1 shows the PCR confirmation of the knockouts.

As is shown in Figure 2a, extramitochondrial $\mathrm{Ca}^{2+}$ was sequestered in the mitochondria of control cells and released by the uncoupler FCCP. In agreement with a previous report [20], both TcMICU1-KO and TcMICU2-KO epimastigotes showed a reduced capacity for mitochondrial $\mathrm{Ca}^{2+}$ uptake (Figure $2 \mathrm{~b}, \mathrm{c}$ ). This activity was inhibited by Ru360, added prior to the delivery of $30 \mu \mathrm{M} \mathrm{Ca}^{2+}$ in the presence of succinate as an energy source, in a dose-dependent manner, and with an $\mathrm{IC}_{50}$ of $185.9 \pm 15.2 \mathrm{nM}$. As shown in Figure 2e, a sigmoidal fit is displayed for this inhibition. RuRed (Figure 2d) and Ru265 (Figure 2f) also inhibited mitochondrial $\mathrm{Ca}^{2+}$ uptake in a dose-dependent mode with $\mathrm{IC}_{50} \mathrm{~S}$ of $117 \pm 16.9 \mathrm{nM}$ and $26.3 \pm 2.0 \mathrm{nM}$, respectively. 
a

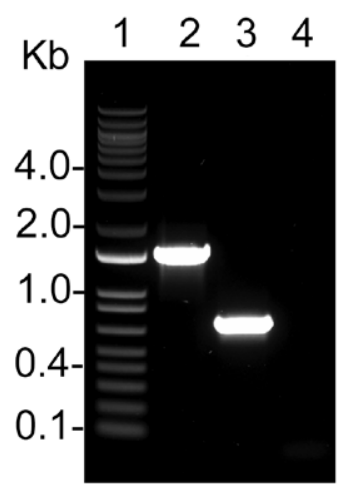

b

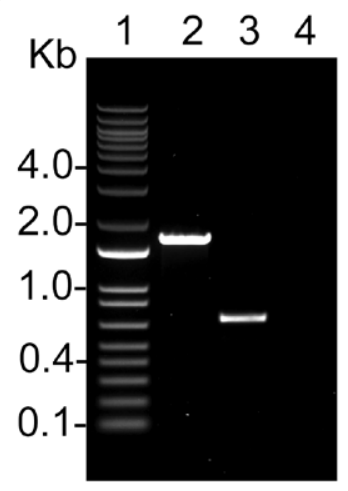

Figure 1. PCR confirmation of TcMICU1-KO and TcMICU2-KO. (a) TcMICU1-KO mutant was generated by CRISPR/Cas9-induced homologous recombination. A double-stranded gDNA break was produced by Cas 9 at $n t+70$ of the TcMICU1 ORF $(1221 \mathrm{bp})$. DNA was repaired with a blasticidin-S deaminase (Bsd) cassette containing 100-bp homologous regions from TcMICU1 5' and $3^{\prime}$ untranslated regions (UTRs). The gene replacement was verified by PCR. The intact locus generates a PCR product of $1544 \mathrm{bp}$, while the disrupted locus generates a fragment of $722 \mathrm{bp}$. (b) TcMICU2-KO mutant was generated by CRISPR/Cas9-induced homologous recombination. A double-stranded gDNA break was produced by Cas 9 at $n t+84$ of the TcMICU2 ORF (1407 bp). DNA was repaired with a blasticidin-S deaminase (Bsd) cassette containing 100-bp homologous regions from TcMICU2 5' and $3^{\prime}$ untranslated regions (UTRs). The gene replacement was verified by PCR. The intact locus generates a PCR product of $1701 \mathrm{bp}$, while the disrupted locus generates a fragment of $693 \mathrm{bp}$. Lanes: 1, 1-kb ladder; 2, wild type; 3, TcMICU1-KO (a) or TcMICU2-KO (b); 4, PCR negative controls.

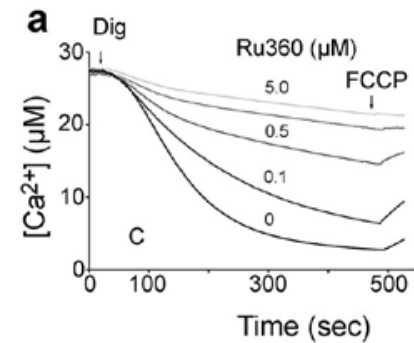

d

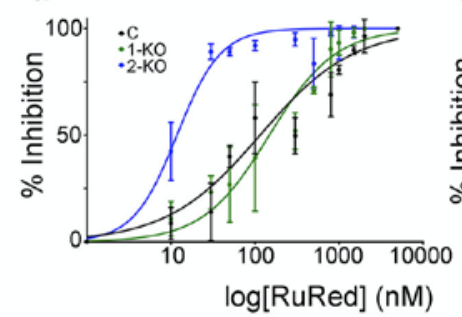

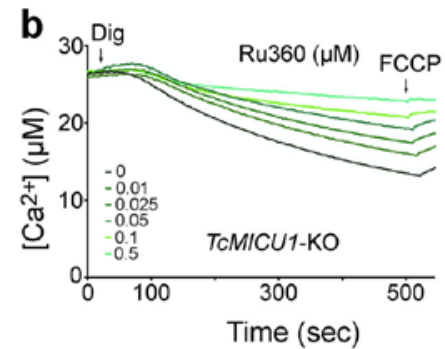

e

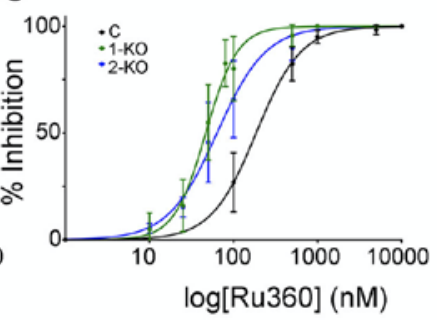

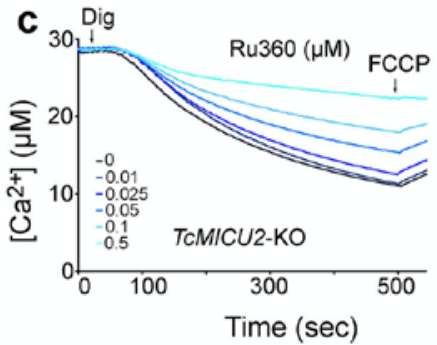

f

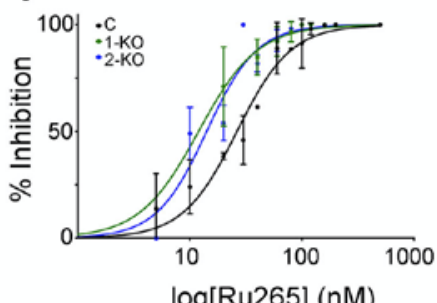

Figure 2. Inhibition of mitochondrial $\mathrm{Ca}^{2+}$ uptake by ruthenium-based compounds. Representative traces of $\mathrm{Ca}^{2+}$ uptake by digitonin-permeabilized epimastigotes in control (a), TcMICU1-KO (b), and TcMICU2-KO (c) epimastigotes in the presence of different Ru360 concentrations. C, control cells; TcMICU1-KO cells; and TcMICU2-KO cells. The reaction was started after adding $50 \mu \mathrm{M}$ digitonin (Dig) in the presence of $\sim 30 \mu \mathrm{M} \mathrm{CaCl}_{2}, 5 \mathrm{mM}$ succinate, and $0.5 \mu \mathrm{M}$ calcium green-5N, in the presence or absence of Ru360. Where indicated, $4 \mu \mathrm{M}$ FCCP was added. (d-f) Dose-response inhibition of the initial rate of mitochondrial $\mathrm{Ca}^{2+}$ uptake in control (C), TcMICU1-KO (1-KO), and TcMICU2-KO (2-KO) cells treated with RuRed (d), Ru360 (e) or Ru265 (f). A sigmoidal fit is displayed for each.

When dose-response effects were measured in TcMICU1-KO and TcMICU2-KO cells we noticed that these cells were, in general, more sensitive to the inhibitors. For example, $\mathrm{IC}_{50} \mathrm{~s}$ values for Ru360 
in TcMICU1-KO and TcMICU2-KO cells were $46.7 \pm 2.7 \mathrm{nM}(p<0.0001)$ and $63.6 \pm 6.9 \mathrm{nM}(p<0.0002)$, respectively (Figure 2e), and the $\mathrm{IC}_{50}$ values for Ru265 were $12.1 \pm 2.3 \mathrm{nM}(p<0.003)$ and $14.1 \pm 1.3 \mathrm{nM}$ $(p<0.007)$, respectively (Figure 2f). In contrast, in the presence of RuRed a significant increase in sensitivity was observed only in TcMICU2-KO cells with an $\mathrm{IC}_{50}$ of $11.9 \pm 1.4 \mathrm{nM}(p<0.005)$, while for TcMICU1-KO cells the $\mathrm{IC}_{50}$ was similar to that of control cells $(148 \pm 21.7 \mathrm{nM})(p<0.353$, n.s.) (Figure $2 \mathrm{~d})$.

To determine whether the defect in mitochondrial $\mathrm{Ca}^{2+}$ uptake in the presence of inhibitors was not secondary to mitochondrial membrane depolarization, we measured the mitochondrial membrane potential $\left(\Delta \psi_{\mathrm{m}}\right)$ of digitonin-permeabilized epimastigotes using safranine $\mathrm{O}$ in the presence of succinate as mitochondrial substrate.

Figure $3 \mathrm{a}-\mathrm{c}$ show that the addition of ADP to these preparations caused a small decrease in the $\Delta \psi_{\mathrm{m}}$ that returned to its normal level when the adenine nucleotide translocator (ANT) inhibitor carboxyatractyloside was added to inhibit ADP/ATP exchange, while the addition of FCCP collapsed $\Delta \psi_{\mathrm{m}}$. The presence of either RuRed, Ru360 or Ru265 did not significantly affect the $\Delta \psi_{\mathrm{m}}$ of control, TcMICU1-KO or TcMICU2-KO (Figure 3d) cells, or their response to ADP (Figure 3e-g). Figure 3a shows that the addition of $\mathrm{Ca}^{2+}$ caused membrane depolarization in control cells that returned to basal levels after the addition of EGTA, but no changes were observed when ruthenium-derivatives were present.
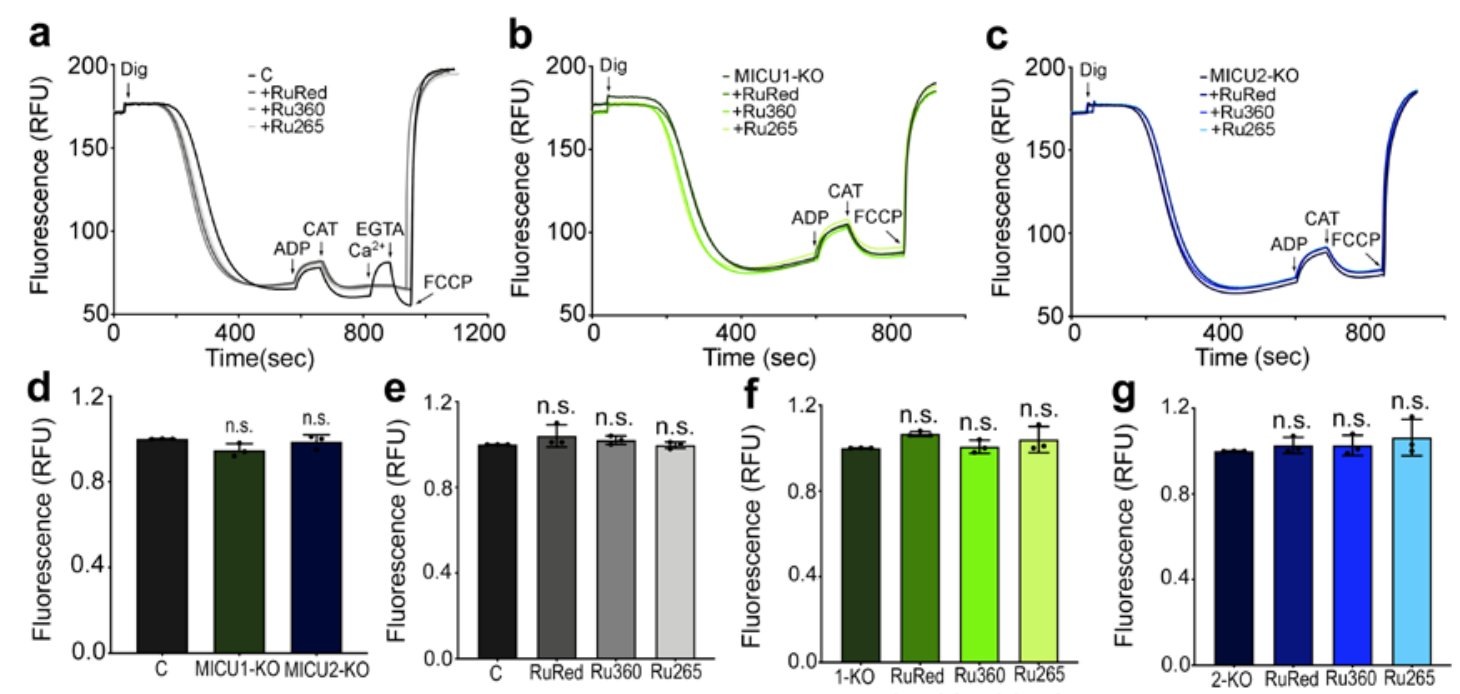

Figure 3. Effect of inhibitors on the mitochondrial membrane potential of epimastigotes. Changes in mitochondrial membrane potential $\left(\Delta \psi_{\mathrm{m}}\right)$ of digitonin-permeabilized epimastigotes as detected by changes in safranine O fluorescence in control (a), TcMICU1-KO (b), and TcMICU2-KO (c) epimastigotes in the absence or presence of inhibitors. Cells $\left(5 \times 10^{7}\right)$ were added to the reaction buffer $(2 \mathrm{~mL})$ containing $0.2 \%$ BSA, $5 \mathrm{mM}$ succinate, $50 \mu \mathrm{M}$ EGTA and $5 \mu \mathrm{M}$ safranine $\mathrm{O}$. The reaction was started with $50 \mu \mathrm{M}$ digitonin (DIG) in the presence or absence of the inhibitor, and $250 \mu \mathrm{M} A D P, 1.5 \mu \mathrm{M}$ carboxyatractyloside (CAT), $50 \mu \mathrm{M} \mathrm{CaCl}_{2}\left(\mathrm{Ca}^{2+}\right), 200 \mu \mathrm{M}$ EGTA, and $4 \mu \mathrm{M}$ FCCP were added when indicated. A decrease in fluorescence after permeabilization with digitonin indicated the accumulation of the dye in energized mitochondria. The addition of ADP produced a small dissipation of membrane potential, indicating ADP phosphorylation. $\Delta \psi_{\mathrm{m}}$ returned to its initial level after the addition of the adenine nucleotide translocator inhibitor CAT. The addition of FCCP collapsed the membrane potential. (d) Changes in safranine $\mathrm{O}$ fluorescence after digitonin addition (between 30 and $60 \mathrm{~s}$ ) in control (C), TcMICU1-KO and TcMICU2-KO epimastigotes. Values are means $\pm \mathrm{SD}(n=3)$. n.s., no significant differences by one-way ANOVA with Dunnett's multiple comparisons test. Changes in safranine O fluorescence in control (C) (e), TcMICU1-KO (1-KO) (f), and TcMICU2-KO (2-KO) (g) epimastigotes after addition of ADP from three experiments like that shown in panels $(\mathbf{a}-\mathbf{c})$. In the panels, $(\mathbf{e}-\mathbf{g})$, values are means $\pm \mathrm{SD}(n=3)$. n.s., no significant differences by one-way ANOVA with Dunnett's multiple comparisons test. 


\subsection{Effects of Ru265 on Trypanosoma cruzi}

Knockout of different subunits of T. cruzi MCU complex results in phenotypic changes that include delayed growth, alterations in their respiratory rate, and defects in trypomastigote invasion and amastigote replication $[17,19]$. Because Ru265 is apparently more cell-permeable than other ruthenium derivatives [30], we tested whether it affects epimastigote growth, and respiration, and trypomastigote attachment to host cells, which is an energy-requiring process required for host cell invasion [31].

We analyzed the growth rate of epimastigotes in LIT medium at different Ru265 concentrations $(1 \mu \mathrm{M}, 5 \mu \mathrm{M}$, and $10 \mu \mathrm{M})$. This assay revealed that Ru265 does not affect the growth rate of control parasites and is nontoxic at the concentrations tested (Figure 4a). The presence of metabolic inhibitors affects attachment and invasion of T. cruzi trypomastigotes to mammalian cells since these are an active process which depends on the expenditure of parasite energy [31]. Preincubation of trypomastigotes for 30 min with antimycin A, which blocks electron transport from cytochrome $b$ to $c_{1}$, decreased the ability of trypomastigotes to attach to glutaraldehyde-fixed cells (Figure $4 \mathrm{~b}$ ) and invade intact host cells (Figure 4c). However, the ability of trypomastigotes to attach glutaraldehyde-fixed cells and invade intact cells was not affected by a similar preincubation with $10 \mu \mathrm{M}$ Ru265.

To measure the effect of this compound on parasite respiration, epimastigotes were preincubated in the presence (Figure $4 \mathrm{~d}$ ) or absence (Figure $4 \mathrm{e}$ ) of Ru265. The rates of oxygen consumption by the parasites were measured after the addition of cells, oligomycin A, and finally uncoupled by sequential additions of FCCP to determine the routine respiration (initial oxygen flux values), leak respiration, and the electron transport system (ETS) capacity, respectively (Figure 4f) [32]. Uncoupled respiratory control rates, which are expressed as the ratio of the uncoupled rate (state $3 u$ ) to the rate when oligomycin is present, were $1.75 \pm 0.05$ and $1.70 \pm 0.04$ for control cells in the absence and presence of Ru265, respectively $(n=3)$. Moreover, the spare respiratory capacity, which is the ability of substrate supply and electron transport to respond to an increase in energy demand, was $93.71 \pm 5.87$ and $91.61 \pm 10.6$ for control cells in the presence or absence of Ru265, respectively, $(n=3)$. This is measured by the difference between state $3 u$ and the basal rate [32]. Our results demonstrate that Ru265 did not affect $\mathrm{O}_{2}$ consumption level when we compared it with that of parasites without inhibitor (Figure $4 \mathrm{f}$ ).

To determine if Ru265 could inhibit mitochondrial $\mathrm{Ca}^{2+}$ uptake in intact non-permeablized cells, epimastigotes were loaded with the mitochondrial $\mathrm{Ca}^{2+}$ indicator Rhod-2 AM in the presence or the absence of $50 \mu \mathrm{M}$ Ru265. Cells were treated with the combination of nigericin and ionomycin, which is known to release $\mathrm{Ca}^{2+}$ from neutral and acidic compartments (acidocalcisomes) [33], and $\mathrm{Ca}^{2+}$ was rapidly taken up by the mitochondria (Figure $4 \mathrm{~g}$ ). Rhod-2 fluorescence increased after this treatment indicating mitochondrial $\mathrm{Ca}^{2+}$ uptake, and slowly decreased after reaching a peak. The addition of the uncoupler FCCP increased the rate of $\mathrm{Ca}^{2+}$ release indicating that $\mathrm{Ca}^{2+}$ was being released from the mitochondria and reached a new steady-state level. There was no significant difference in the amount of $\mathrm{Ca}^{2+}$ taken up by control and Ru265-treated cells in three independent experiments (Figure 4h), again suggesting the low permeability for Ru265 in trypanosomes.

In conclusion, preincubations with different concentrations of Ru265 did not affect growth, respiration, mitochondrial $\mathrm{Ca}^{2+}$ uptake, or host cell attachment and invasion, suggesting that it is not as permeable in trypanosomes as in mammalian cells. 

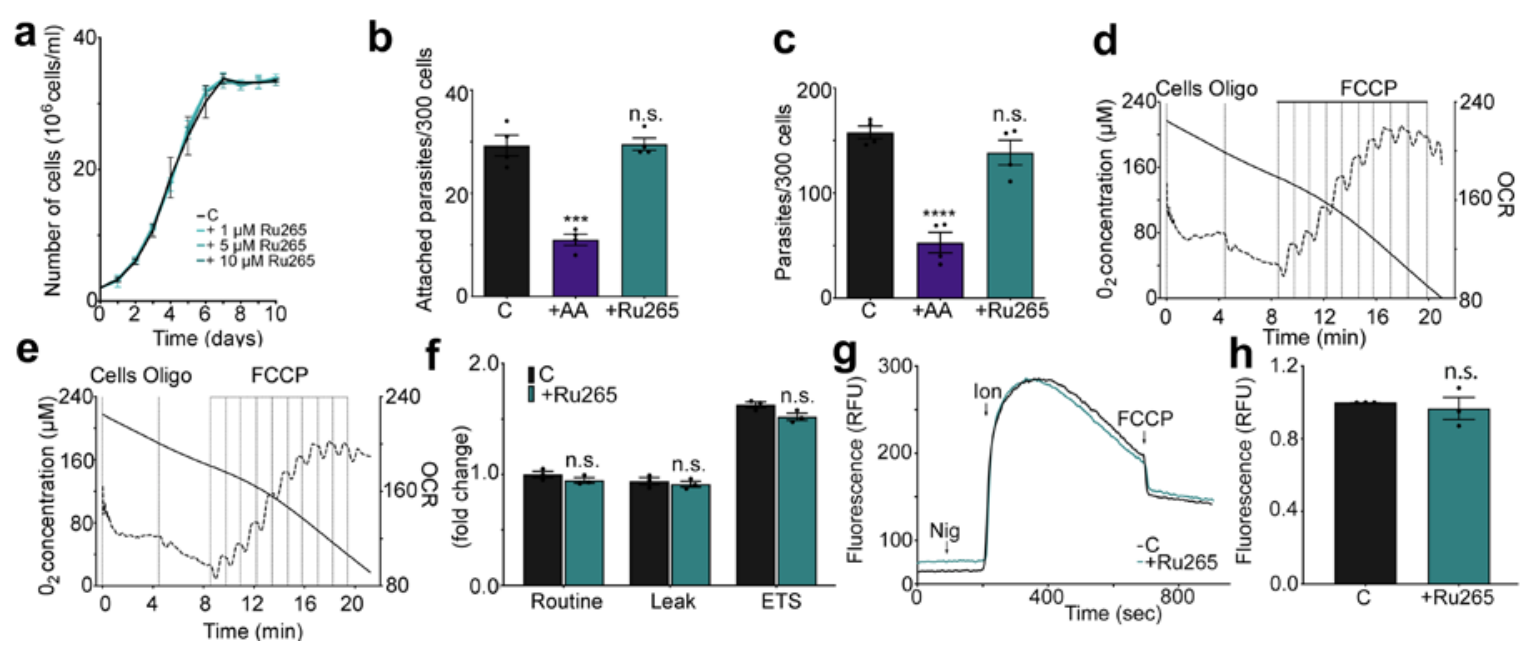

Figure 4. Effect of Ru265 on Trypanosoma cruzi. (a) Effect of Ru265 on epimastigote growth. Growth of control epimastigotes in LIT medium in the presence of $1 \mu \mathrm{M}, 5 \mu \mathrm{M}$, and $10 \mu \mathrm{M}$ Ru265. (b) Effect of Ru265 on trypomastigote attachment. Trypomastigotes were pretreated for 30 min with $1 \mu \mathrm{M}$ antimycin A (AA) or $10 \mu \mathrm{M}$ Ru265 and added to glutaraldehyde-fixed Vero cells. After $1 \mathrm{~h}$ of incubation at $37^{\circ} \mathrm{C}$, the cells were washed, and the number of attached trypomastigotes was counted. Values are means $\pm \mathrm{SD}(n=4)$. n.s., no significant differences; ${ }^{* * *} p<0.001$; by one-way ANOVA with Dunnett's multiple comparisons. (c) Effect of Ru265 on trypomastigotes infection. Trypomastigotes were pretreated for 30 min with $1 \mu \mathrm{M}$ antimycin A or $10 \mu \mathrm{M}$ Ru265 and added to Vero cells. After $4 \mathrm{~h}$ of incubation at $37^{\circ} \mathrm{C}$, the cells were washed, and the number of intracellular parasites was counted. Values are means $\pm \mathrm{SD}$ $(n=4)$. n.s., no significant differences; ${ }^{* * * *} p<0.0001$; by one-way ANOVA with Dunnett's multiple comparisons test. n.s., no significant differences by Student's $t$-test. (d,e) Representative traces of oxygen consumption rate (OCR in Pmol/sec.mg) in control epimastigotes after preincubation without (d) or with (e) $10 \mu \mathrm{M}$ Ru265 for $5 \mathrm{~min}$. The dashed lines indicate the variation in oxygen concentration as a function of time (right axis). The solid lines represent $\mathrm{O}_{2}$ concentration (left axis). Where indicated, $0.5 \mu \mathrm{g} / \mathrm{mL}$ oligomycin (oligo) was added, followed by sequential additions of FCCP $(0.2 \mu \mathrm{M}$ each). (f) Routine respiration (initial oxygen flux values), leak respiration after the addition of $0.5 \mu \mathrm{g} / \mathrm{mL}$ of oligomycin A, and electron transfer system (ETS) capacity after the sequential additions of FCCP $(0.2 \mu \mathrm{M}$ each) were measured for each condition. Values are means $\pm \mathrm{SD}(n=3)$. n.s, no significant differences, by two-way ANOVA with Sidak's multiple-comparison test. (g) Representative experiment showing mitochondrial $\mathrm{Ca}^{2+}$ uptake by intact epimastigotes in relative fluorescence units (RFU). Cells $\left(5 \times 10^{7}\right)$ were loaded with the mitochondrial calcium indicator Rhod-2 AM and pretreated with or without $50 \mu \mathrm{M}$ Ru265 for $30 \mathrm{~min}$. Cells were incubated with $1 \mu \mathrm{M}$ nigericin (Nig) and $1 \mu \mathrm{M}$ ionomycin (Ion) to rapidly elevate cytosolic $\mathrm{Ca}^{2+}$ levels and induce mitochondrial $\mathrm{Ca}^{2+}$ uptake. The addition of $8 \mu \mathrm{M}$ FCCP increased the release of mitochondrial $\mathrm{Ca}^{2+}$. (h) Changes in fluorescence (before and after ionomycin addition) from three experiments like that shown in panel (g). Values are means $\pm \mathrm{SD}(n=3)$, n.s., no significant differences.

\section{Discussion}

The most important findings of this work are: (1) Ru360 and Ru265 are nM inhibitors of the MCU complex of T. cruzi with Ru265 being the most effective, with an $\mathrm{IC}_{50}$ of only $26.3 \pm 2.0 \mathrm{nM}$; (2) ablation of either TcMICU1 or TcMICU2 increased the sensitivity of TcMCU complex to Ru360 and Ru265; and (3) application of Ru265 to intact cells did not significantly affect epimastigotes growth or respiration, mitochondrial $\mathrm{Ca}^{2+}$ uptake in intact cells, and trypomastigote attachment and invasion of host cells, suggesting low permeability in trypanosomes.

RuRed has been used routinely to inhibit the MCU complex of trypanosomes, but this is the first time a dose-response effect has been tested with mitochondria in situ and its activity compared with that of more potent inhibitors, like Ru360 and Ru265. The IC 50 of RuRed, Ru360 and Ru265 are in the nanomolar range. However, it is important to note that while RuRed is effective in the submicromolar 
range [34], Ru360 is effective with an $\mathrm{IC}_{50}$ between 0.2 and $2 \mathrm{nM} \mathrm{[25]} \mathrm{in} \mathrm{mammalian} \mathrm{mitochondria,}$ suggesting that the TcMCU complex is less sensitive to Ru360. Although ruthenium-derivatives could have secondary effects, such as stimulation of $\mathrm{Ca}^{2+}$ release from the endoplasmic reticulum (ER) [35], we do not expect this to occur in our mitochondrial in situ preparations because of lack of ER $\mathrm{Ca}^{2+}$ accumulation in the absence of ATP, which is diluted in the medium.

MICU1-deficient mitochondria of mammalian cells were found to be more sensitive to RuRed or Ru360 inhibition of $\mathrm{Ca}^{2+}$ uptake than control mitochondria [29]. This was attributed to the presence of a DIME-interacting domain (DID) in MICU1, comprising two arginines (R440 and R443) and responsible for the interaction of MICU1 and the exposed D-ring of MCU oligomer. This interaction is required for keeping the MCU complex pore closed at low cytosolic $\mathrm{Ca}^{2+}$ concentrations $\left(\left[\mathrm{Ca}^{2+}\right]_{\mathrm{c}}\right)$ and optimally activated at high $\left[\mathrm{Ca}^{2+}\right]_{\mathrm{c}}[29]$. This interaction also controls the complex accessibility for its inhibitors, which would also interact with the D-ring of the MCU oligomers [26,27]. Interestingly, the two arginines of the DID are conserved among the three mammalian MICUs [29] as well as in TcMICU1 and TcMICU2 [20]. However, only mitochondria of MICU1-KO mammalian cells were tested [29]. In this work, we show that mitochondria of both TcMICU1-KO and TcMICU2-KO cells are more sensitive to Ru360 and Ru265 inhibition. The results suggest that both TcMICU1 and TcMICU2 would interact with the D-ring of the TcMCU oligomer and that in the absence of any of them, the complex becomes more accessible and more sensitive to inhibition by ruthenium-derivatives. In mammalian cells, ablation of MICU1 leads to decreased protein levels of MICU2 [14]. It is possible that this does not occur in trypanosomes, and upon ablation of one of them, the other subunit is still able to act as a gatekeeper of the channel. The interaction of both proteins with the D-ring would explain why individual ablation of each TcMICU protein does not increase $\mathrm{Ca}^{2+}$ uptake at low $\left[\mathrm{Ca}^{2+}\right]_{\mathrm{c}}[20]$, as it occurs in mammalian cells [23], as the other subunit will still be present. In mammalian cells, the threshold for $\mathrm{Ca}^{2+}$ uptake is affected by the loss of either MICU1 or MICU2, as shown by increased uptake rate when given $\left[\mathrm{Ca}^{2+}\right]_{\mathrm{c}}$ below the threshold [23].

It is possible that the different sensitivity of mitochondria of trypanosomes to ruthenium derivatives is due to the different composition of the TcMCU complex. The pore of the TcMCU complex is formed by the contribution of different monomers (MCU, MCUb, MCUc, and MCUd) in contrast to the homo-oligomeric nature of the mammalian uniporter. Finally, experiments with intact cells suggest that ruthenium derivatives have low permeability in trypanosomes. It is interesting to note that prolonged incubation times with high concentrations of Ru265 were needed to see effects on respiration in mouse cortical neurons [36]. The reason for the different permeability to Ru265 could be related to the differences in membrane composition. T. cruzi plasma membrane is rich in ergosterol and GPI-anchored proteins [37], and it has been reported that the sterol composition affects its sensitivity to digitonin permeabilization [38]. New derivatives with increased permeability will be needed to study the function of the TcMCU complex in vivo.

\section{Materials and Methods}

\subsection{Chemicals and Reagents}

Calcium green-5N was from Thermo Fisher Scientific (Waltham, MA, USA). Blasticidin $\mathrm{S} \mathrm{HCl}$ was purchased from Life Technologies (Grand Island, NY, USA). Ruthenium red, ruthenium 360, carboxyatractyloside (CAT), oligomycin, safranine $\mathrm{O}$, antimycin A, carbonylcyanide p-trifluoromethoxyphenylhydrazone (FCCP), oligomycin A, G418, and all other reagents of analytical grade were from Sigma (St. Louis, MO, USA). Ru265 was a gift from Justin J. Wilson and Muniswamy Madesh (Department of Medicine, University of Texas Health San Antonio, San Antonio, TX, USA).

\subsection{Culture Methods}

T. cruzi epimastigotes ( $Y$ strain) were grown in liver infusion tryptose (LIT) medium (5.4 mM KCl, $150 \mathrm{mM} \mathrm{NaCl}, 24 \mathrm{mM}$ glucose, $5 \%$ [vol/vol] liver extract, $0.02 \%$ [wt/vol] hemin, $2 \%$ [wt/vol] yeast 
extract, $1.5 \%$ [wt/vol] tryptose) [39] containing $10 \%$ heat-inactivated newborn calf serum at $28{ }^{\circ} \mathrm{C}$. Mutant cell lines were maintained in medium containing $250 \mu \mathrm{g} / \mathrm{mL}$ G418 and $10 \mu \mathrm{g} / \mathrm{mL}$ blasticidin. The growth rate of epimastigotes was determined by counting cells in a Beckman Coulter analyzer. Tissue culture cell-derived trypomastigotes were obtained from Vero cells infected with metacyclic trypomastigotes. T. cruzi trypomastigote forms were collected from the culture medium of infected host cells, using a modification of the method of Schmatz and Murray as described previously [40]. Vero cells were grown in RPMI supplemented with $10 \%$ fetal bovine serum and maintained at $37^{\circ} \mathrm{C}$ with $5 \% \mathrm{CO}_{2}$.

\section{3. $\mathrm{Ca}^{2+}$ Uptake by Digitonin-Permeabilized T. cruzi Epimastigotes}

Cells were collected by centrifugation at $1000 \times \mathrm{g}$ for $7 \mathrm{~min}$ and washed twice with buffer $\mathrm{A}$ with glucose (BAG: $116 \mathrm{mM} \mathrm{NaCl}, 5.4 \mathrm{mM} \mathrm{KCl}, 0.8 \mathrm{mM} \mathrm{MgSO}_{4}, 5.5 \mathrm{mM}$ D-glucose, and $50 \mathrm{mM}$ HEPES, pH 7.0). Epimastigotes were resuspended to a final density of $1 \times 10^{9}$ cells $/ \mathrm{mL}$ in BAG and kept on ice. Before each experiment, a $50 \mu \mathrm{L}$ aliquot of $T$. cruzi epimastigotes $\left(5 \times 10^{7}\right.$ cells $)$ was added to the reaction buffer ( $125 \mathrm{mM}$ sucrose, $65 \mathrm{mM} \mathrm{KCl}, 10 \mathrm{mM}$ HEPES-KOH buffer, $\mathrm{pH} 7.2$, $1 \mathrm{mM} \mathrm{MgCl} 2,2.5 \mathrm{mM}$ potassium phosphate [1.95 mL]) containing $5 \mathrm{mM}$ succinate, $50 \mu \mathrm{M}$ EGTA, and $0.5 \mu \mathrm{M}$ fluorescent cell-impermeable $\mathrm{Ca}^{2+}$ indicator calcium green-5N. Mitochondrial $\mathrm{Ca}^{2+}$ uptake was initiated by the addition of $\sim 30 \mu \mathrm{M}$ of free calcium, which was calculated using the software Maxchelator Calculator v1.2 (https://somapp.ucdmc.ucdavis.edu/pharmacology/bers/maxchelator/ CaEGTA-NIST.htm). This calcium addition was followed by $50 \mu \mathrm{M}$ digitonin and $4 \mu \mathrm{M}$ FCCP. Fluorescence changes were monitored in an F-7000 fluorescence spectrophotometer (Hitachi, Dallas, TX, USA) with excitation at $506 \mathrm{~nm}$ and emission at $532 \mathrm{~nm}$. The relative rates of $\mathrm{Ca}^{2+}$ uptake were normalized for the control strains. The hyperbolic equation $\left[\mathrm{Ca}^{2+}\right]=K_{d} \times\left[\left(F-F_{\min }\right) /\left(F_{\max }-F\right)\right]$ was used to convert the raw fluorescence readings measured during mitochondrial $\mathrm{Ca}^{2+}$ transport assays into $\mathrm{Ca}^{2+}$ concentration levels, where $K_{d}$ is the dissociation constant, $F$ is any given fluorescence value, $F_{\min }$ is the lowest fluorescence reading after addition of $0.5 \mathrm{mM} \mathrm{EGTA}$, and $F_{\max }$ is the maximal fluorescence obtained after two sequential additions of $1 \mathrm{mM} \mathrm{CaCl}_{2}$. These additions were performed at the end of each trace. $K_{d}$ for $\mathrm{Ca}^{2+}$ indicator probes in our conditions was determined, according to Chweih et al. [41]. Uptake rate inhibitions were calculated as the first derivative of the absolute values of the slope by using the SLOPE Excel function for 200 points (300 to $500 \mathrm{~s}$ ). Slope values were transformed into logarithm values and normalized as percentage values. Dose-response curves were compiled, fitting the normalized values in a sigmoidal curve.

\subsection{Mitochondrial Membrane Potential}

Estimation of mitochondrial membrane potential in situ was done spectrofluorometrically using the indicator dye safranine $\mathrm{O}$, as described previously [19]. Briefly, $T$. cruzi epimastigotes $\left(5 \times 10^{7}\right.$ cells) were incubated at $28^{\circ} \mathrm{C}$ in reaction buffer $(125 \mathrm{mM}$ sucrose, $65 \mathrm{mM} \mathrm{KCl}, 10 \mathrm{mM}$ HEPES-KOH buffer, $\mathrm{pH} 7.2,1 \mathrm{mM} \mathrm{MgCl} 2,2.5 \mathrm{mM}$ potassium phosphate [1.95 mL]) containing $5 \mathrm{mM}$ succinate, $0.2 \% \mathrm{BSA}$, $50 \mu \mathrm{M}$ EGTA, and $5 \mu \mathrm{M}$ safranine $\mathrm{O}$, and the reaction was started with digitonin $(50 \mu \mathrm{M})$. ADP $(250 \mu \mathrm{M})$, carboxyatractyloside $(1.5 \mu \mathrm{M})$, and FCCP $(4 \mu \mathrm{M})$ were added to the medium at different time points. Fluorescence changes were monitored using the Hitachi F-7000 spectrofluorometer (excitation of $495 \mathrm{~nm}$ and emission of $586 \mathrm{~nm}$ ).

\subsection{Cellular Respiration}

Cells were collected by centrifugation at $1000 \times g$ for $7 \mathrm{~min}$ and washed twice with buffer A with glucose (BAG: $116 \mathrm{mM} \mathrm{NaCl}, 5.4 \mathrm{mM} \mathrm{KCl}, 0.8 \mathrm{mM} \mathrm{MgSO}_{4}, 5.5 \mathrm{mM}$ D-glucose, and $50 \mathrm{mM}$ HEPES, $\mathrm{pH}$ 7.0). Epimastigotes were resuspended to a final density of $1 \times 10^{9}$ cells $/ \mathrm{mL}$ in BAG and kept on ice. Cells $\left(1 \times 10^{8}\right)$ were incubated at $28^{\circ} \mathrm{C}$ in a $2 \mathrm{~mL}$ chamber containing buffer A with glucose (with or without $10 \mu \mathrm{M}$ Ru265). Oligomycin $(5 \mu \mathrm{g} / \mathrm{mL})$ and FCCP $(0.2 \mu \mathrm{M})$ were sequentially added. The oxygen consumption rates of epimastigotes were measured using a high-resolution respirometer 
(Oroboros Oxygraph-2k; Oroboros Instruments GmbH, Innsbruck, Austria). The equipment was calibrated as reported by its manufacturer. OCR was calculated as the negative time derivative of the oxygen concentration measured in the close respirometer chambers and expressed per milligram of protein.

\subsection{Measurement of Mitochondrial $\mathrm{Ca}^{2+}$ Uptake in Intact Epimastigotes Using Rhod-2 AM}

Cells were collected by centrifugation at $1000 \times g$ for $7 \mathrm{~min}$ and washed twice with buffer A with glucose (BAG: $116 \mathrm{mM} \mathrm{NaCl}, 5.4 \mathrm{mM} \mathrm{KCl}, 0.8 \mathrm{mM} \mathrm{MgSO}_{4}, 5.5 \mathrm{mM}$ D-glucose, and $50 \mathrm{mM}$ HEPES at $\mathrm{pH}$ 7.0). Epimastigotes were resuspended to a final density of $1 \times 10^{9}$ cells $/ \mathrm{mL}$ in BAG and loaded with Rhod-2 AM ( $2 \mu \mathrm{M} ; 50 \mathrm{~min})$. The cells were washed twice with buffer A with glucose and pretreated with or without $50 \mu \mathrm{M}$ Ru265 for $30 \mathrm{~min}$. Before each experiment, a $50 \mu \mathrm{L}$ aliquot of epimastigotes $\left(5 \times 10^{7}\right.$ cells $)$ was added to the BAG. Mitochondrial $\mathrm{Ca}^{2+}$ uptake occurred after the addition of $1 \mu \mathrm{M}$ nigericin (Nig) and $1 \mu \mathrm{M}$ ionomycin (Ion) to rapidly release $\mathrm{Ca}^{2+}$ from neutral and acidic compartments. The addition of $8 \mu \mathrm{M}$ FCCP increased the release of mitochondrial $\mathrm{Ca}^{2+}$. Fluorescence changes were monitored in an F-7000 fluorescence spectrophotometer (Hitachi) with excitation at $552 \mathrm{~nm}$ and emission at $581 \mathrm{~nm}$.

\subsection{Attachment Assay}

Gamma-irradiated (2000 rads) Vero cells were grown at $37^{\circ} \mathrm{C}$ in 24 -well plates on a $13 \mathrm{~mm}$-diameter round glass coverslip at a density of $2 \times 10^{5}$ cells/well in $7 \% \mathrm{CO}_{2}$ in RPMI medium plus $10 \%$ fresh fetal bovine serum. After $24 \mathrm{~h}$, the medium was removed, and the cells were washed twice with Hanks solution and prefixed for $5 \mathrm{~min}$ at $4{ }^{\circ} \mathrm{C}$ with $2 \%$ glutaraldehyde in phosphate-buffered saline (PBS). After fixation, the cells were immediately washed with PBS. Prior to incubation with the cells, the parasites were preincubated with $1 \mu \mathrm{M}$ antimycin A or $10 \mu \mathrm{M}$ Ru265. After $30 \mathrm{~min}$ of incubation at $37^{\circ} \mathrm{C}$, the parasites were seeded onto Vero cells $\left(5 \times 10^{6}\right.$ parasites/well). After $1 \mathrm{~h}$ of incubation at $37^{\circ} \mathrm{C}$, the coverslips were washed once with PBS and mounted onto glass slides in Fluoromount-G containing $15 \mu \mathrm{g} / \mathrm{mL}$ of 2-(4-aminophenyl)-1H-indole-6-carboxamidine (DAPI), which stains host and parasite DNA. Coverslips were viewed on an Olympus BX60 microscope to quantify the number of host cells that contained adherent parasites and the number of adherent parasites per cell in randomly selected fields. Three hundred host cells were counted per sample in four independent experiments.

\subsection{In Vitro Infection Assay}

Gamma-irradiated (2000 rads) Vero cells $\left(4.5 \times 10^{5}\right.$ cells) were plated onto sterile coverslips in a 12-well plate and incubated overnight at $35^{\circ} \mathrm{C}$ in $7 \% \mathrm{CO}_{2}$ in RPMI medium plus $10 \%$ fresh fetal bovine serum. Tissue culture-derived trypomastigote collections were incubated at $4{ }^{\circ} \mathrm{C}$ overnight to allow amastigotes to settle from swimming trypomastigotes. Trypomastigotes from the supernatants of these collections were counted and used to infect the coverslips at a ratio of 50 parasites to 1 host cell. Prior to incubation with the cells, the parasites were preincubated with $1 \mu \mathrm{M}$ antimycin A or $10 \mu \mathrm{M}$ Ru265 for $30 \mathrm{~min}$. At $4 \mathrm{~h}$ post-infection, coverslips were washed extensively with Hanks' solution, followed by phosphate-buffered saline (PBS) at pH 7.4 to remove any extracellular parasites. Coverslips were fixed immediately in $4 \%$ paraformaldehyde in PBS (pH 7.4) at $4{ }^{\circ} \mathrm{C}$ for $30 \mathrm{~min}$. Coverslips were washed once with PBS and mounted onto glass slides in Fluoromount-G containing $15 \mu \mathrm{g} / \mathrm{mL}$ of 2-(4-aminophenyl)-1H-indole-6-carboxamidine (DAPI), which stains host and parasite DNA. Coverslips were viewed on an Olympus BX60 microscope to quantify the number of host cells that contained intracellular parasites and the number of intracellular parasites per cell in randomly selected fields. Three hundred host cells were counted per sample in four independent experiments. 


\subsection{Statistical Analysis}

Statistical analyses were performed with GraphPad Prism software version 8.4 (GraphPad, La Jolla, CA, USA). Reported values are means \pm standard deviation (SD) from $n$ biological experiments, as indicated in figure legends. The level of significance was evaluated by one-way analysis of variance (ANOVA) for comparisons between more than two cell lines and two-way ANOVA with multiple-comparison tests for analyses of grouped data.

Author Contributions: Conceptualization, M.S.B. and R.D.; methodology, M.S.B.; validation, M.S.B. and R.D.; formal analysis, M.S.B.; investigation, M.S.B.; resources, R.D.; data curation, M.S.B.; writing-original draft preparation, M.S.B.; writing—review and editing, R.D.; supervision, R.D.; project administration, R.D.; funding acquisition, R.D. Both authors have read and agreed to the published version of the manuscript.

Funding: This work was funded by the National Institute of Allergy and Infectious Diseases of the National Institutes of Health under grant Number AI108222.

Acknowledgments: We thank Justin Wilson and Muniswamy Madesh for Ru265.

Conflicts of Interest: The authors declare no conflict of interest.

\section{Abbreviations}

MCU Mitochondrial calcium uniporter

MICU Mitochondrial calcium uptake

MCUR1 MCU regulator 1

RuRed Ruthenium red

\section{References}

1. McCormack, J.G.; Denton, R.M. $\mathrm{Ca}^{2+}$ as a second messenger within mitochondria. Trends Biochem. Sci. 1986, 11, 258-262. [CrossRef]

2. Denton, R.M. Regulation of mitochondrial dehydrogenases by calcium ions. Biochim. Biophys. Acta 2009, 1787, 1309-1316. [CrossRef] [PubMed]

3. Territo, P.R.; French, S.A.; Dunleavy, M.C.; Evans, F.J.; Balaban, R.S. Calcium activation of heart mitochondrial oxidative phosphorylation: Rapid kinetics of $\mathrm{mVO}_{2}, \mathrm{NADH}, \mathrm{AND}$ light scattering. J. Biol. Chem. 2001, 276, 2586-2599. [CrossRef] [PubMed]

4. Territo, P.R.; Mootha, V.K.; French, S.A.; Balaban, R.S. $\mathrm{Ca}^{2+}$ activation of heart mitochondrial oxidative phosphorylation: Role of the $\mathrm{F}_{0} / \mathrm{F}_{1}$-ATPase. Am. J. Physiol. Cell Physiol. 2000, 278, C423-C435. [CrossRef]

5. Deluca, H.F.; Engstrom, G.W. Calcium uptake by rat kidney mitochondria. Proc. Natl. Acad. Sci. USA 1961, 47, 1744-1750. [CrossRef]

6. Vasington, F.D.; Murphy, J.V. Ca ion uptake by rat kidney mitochondria and its dependence on respiration and phosphorylation. J. Biol. Chem. 1962, 237, 2670-2677.

7. De Stefani, D.; Raffaello, A.; Teardo, E.; Szabo, I.; Rizzuto, R. A forty-kilodalton protein of the inner membrane is the mitochondrial calcium uniporter. Nature 2011, 476, 336-340. [CrossRef]

8. Baughman, J.M.; Perocchi, F.; Girgis, H.S.; Plovanich, M.; Belcher-Timme, C.A.; Sancak, Y.; Bao, X.R.; Strittmatter, L.; Goldberger, O.; Bogorad, R.L.; et al. Integrative genomics identifies MCU as an essential component of the mitochondrial calcium uniporter. Nature 2011, 476, 341-345. [CrossRef]

9. Docampo, R.; Vercesi, A.E. Characteristics of $\mathrm{Ca}^{2+}$ transport by Trypanosoma cruzi mitochondria in situ. Arch Biochem. Biophys. 1989, 272, 122-129. [CrossRef]

10. Docampo, R.; Vercesi, A.E. $\mathrm{Ca}^{2+}$ transport by coupled Trypanosoma cruzi mitochondria in situ. J. Biol. Chem. 1989, 264, 108-111.

11. Carafoli, E.; Balcavage, W.X.; Lehninger, A.L.; Mattoon, J.R. $\mathrm{Ca}^{2+}$ metabolism in yeast cells and mitochondria. Biochim. Biophys. Acta 1970, 205, 18-26. [CrossRef]

12. Perocchi, F.; Gohil, V.M.; Girgis, H.S.; Bao, X.R.; McCombs, J.E.; Palmer, A.E.; Mootha, V.K. MICU1 encodes a mitochondrial $\mathrm{EF}$ hand protein required for $\mathrm{Ca}^{2+}$ uptake. Nature 2010, 467, 291-296. [CrossRef] [PubMed]

13. Mallilankaraman, K.; Cardenas, C.; Doonan, P.J.; Chandramoorthy, H.C.; Irrinki, K.M.; Golenar, T.; Csordas, G.; Madireddi, P.; Yang, J.; Muller, M.; et al. MCUR1 is an essential component of mitochondrial $\mathrm{Ca}^{2+}$ uptake that regulates cellular metabolism. Nat. Cell Biol. 2012, 14, 1336-1343. [CrossRef] 
14. Plovanich, M.; Bogorad, R.L.; Sancak, Y.; Kamer, K.J.; Strittmatter, L.; Li, A.A.; Girgis, H.S.; Kuchimanchi, S.; De Groot, J.; Speciner, L.; et al. MICU2, a paralog of MICU1, resides within the mitochondrial uniporter complex to regulate calcium handling. PLoS ONE 2013, 8, e55785. [CrossRef] [PubMed]

15. Raffaello, A.; De Stefani, D.; Sabbadin, D.; Teardo, E.; Merli, G.; Picard, A.; Checchetto, V.; Moro, S.; Szabo, I.; Rizzuto, R. The mitochondrial calcium uniporter is a multimer that can include a dominant-negative pore-forming subunit. Embo J. 2013, 32, 2362-2376. [CrossRef] [PubMed]

16. Sancak, Y.; Markhard, A.L.; Kitami, T.; Kovacs-Bogdan, E.; Kamer, K.J.; Udeshi, N.D.; Carr, S.A.; Chaudhuri, D.; Clapham, D.E.; Li, A.A.; et al. EMRE is an essential component of the mitochondrial calcium uniporter complex. Science 2013, 342, 1379-1382. [CrossRef]

17. Chiurillo, M.A.; Lander, N.; Bertolini, M.S.; Vercesi, A.E.; Docampo, R. Functional analysis and importance for host cell infection of the $\mathrm{Ca}^{2+}$-conducting subunits of the mitochondrial calcium uniporter of Trypanosoma cruzi. Mol. Biol. Cell 2019, 30, 1676-1690. [CrossRef]

18. Huang, G.; Docampo, R. The mitochondrial $\mathrm{Ca}^{2+}$ uniporter complex (MCUC) of Trypanosoma brucei is a hetero-oligomer that contains novel subunits essential for $\mathrm{Ca}^{2+}$ uptake. mBio 2018, 9, e01700-18. [CrossRef]

19. Chiurillo, M.A.; Lander, N.; Bertolini, M.S.; Storey, M.; Vercesi, A.E.; Docampo, R. Different roles of mitochondrial calcium uniporter complex subunits in growth and infectivity of Trypanosoma cruzi. mBio 2017, 8, e00574-17. [CrossRef]

20. Bertolini, M.S.; Chiurillo, M.A.; Lander, N.; Vercesi, A.E.; Docampo, R. MICU1 and MICU2 play an essential role in mitochondrial $\mathrm{Ca}^{2+}$ uptake, growth, andinfectivity of the human pathogen Trypanosoma cruzi. MBio 2019, 10, e00348-19. [CrossRef]

21. Mallilankaraman, K.; Doonan, P.; Cardenas, C.; Chandramoorthy, H.C.; Muller, M.; Miller, R.; Hoffman, N.E.; Gandhirajan, R.K.; Molgo, J.; Birnbaum, M.J.; et al. MICU1 is an essential gatekeeper for MCU-mediated mitochondrial $\mathrm{Ca}^{2+}$ uptake that regulates cell survival. Cell 2012, 151, 630-644. [CrossRef] [PubMed]

22. Csordas, G.; Golenar, T.; Seifert, E.L.; Kamer, K.J.; Sancak, Y.; Perocchi, F.; Moffat, C.; Weaver, D.; de la Fuente Perez, S.; Bogorad, R.; et al. MICU1 controls both the threshold and cooperative activation of the mitochondrial $\mathrm{Ca}^{2+}$ uniporter. Cell Metab. 2013, 17, 976-987. [CrossRef] [PubMed]

23. Kamer, K.J.; Grabarek, Z.; Mootha, V.K. High-affinity cooperative Ca ${ }^{2+}$ binding by MICU1-MICU2 serves as an on-off switch for the uniporter. Embo Rep. 2017, 18, 1397-1411. [CrossRef] [PubMed]

24. Pittis, A.A.; Goh, V.; Cebrian-Serrano, A.; Wettmarshausen, J.; Perocchi, F.; Gabaldon, T. Discovery of EMRE in fungi resolves the true evolutionary history of the mitochondrial calcium uniporter. Nat. Commun. 2020, 11, 4031. [CrossRef] [PubMed]

25. Ying, W.L.; Emerson, J.; Clarke, M.J.; Sanadi, D.R. Inhibition of mitochondrial calcium ion transport by an oxo-bridged dinuclear ruthenium ammine complex. Biochemistry 1991, 30, 4949-4952. [CrossRef]

26. Arduino, D.M.; Wettmarshausen, J.; Vais, H.; Navas-Navarro, P.; Cheng, Y.; Leimpek, A.; Ma, Z.; Delrio-Lorenzo, A.; Giordano, A.; Garcia-Perez, C.; et al. Systematic identification of MCU modulators by orthogonal interspecies chemical screening. Mol. Cell 2017, 67, 711-723.e7. [CrossRef]

27. Cao, C.; Wang, S.; Cui, T.; Su, X.C.; Chou, J.J. Ion and inhibitor binding of the double-ring ion selectivity filter of the mitochondrial calcium uniporter. Proc. Natl. Acad. Sci. USA 2017, 114, E2846-E2851. [CrossRef]

28. Baradaran, R.; Wang, C.; Siliciano, A.F.; Long, S.B. Cryo-EM structures of fungal and metazoan mitochondrial calcium uniporters. Nature 2018, 559, 580-584. [CrossRef]

29. Paillard, M.; Csordas, G.; Huang, K.T.; Varnai, P.; Joseph, S.K.; Hajnoczky, G. MICU1 interacts with the D-Ring of the MCU pore to control its $\mathrm{Ca}^{2+}$ flux and sensitivity to Ru360. Mol. Cell 2018, 72, 778-785.e3. [CrossRef]

30. Woods, J.J.; Nemani, N.; Shanmughapriya, S.; Kumar, A.; Zhang, M.; Nathan, S.R.; Thomas, M.; Carvalho, E.; Ramachandran, K.; Srikantan, S.; et al. A Selective and cell-permeable mitochondrial calcium uniporter (MCU) inhibitor preserves mitochondrial bioenergetics after hypoxia/reoxygenation injury. ACS Cent. Sci. 2019, 5, 153-166. [CrossRef]

31. Schenkman, S.; Robbins, E.S.; Nussenzweig, V. Attachment of Trypanosoma cruzi to mammalian cells requires parasite energy, and invasion can be independent of the target cell cytoskeleton. Infect. Immun. 1991, 59, 645-654. [CrossRef] [PubMed]

32. Gnaiger, E. Polarographic oxygen sensors, the oxygraph, and high-resolution respirometry to asses mitochondrial function. In Drug-Induced Mitochondrial Disfunction; Dykens, J., Will, Y., Eds.; John Wiley \& Sons: Hoboken, NJ, USA, 2008; pp. 327-352. 
33. Docampo, R.; Scott, D.A.; Vercesi, A.E.; Moreno, S.N. Intracellular $\mathrm{Ca}^{2+}$ storage in acidocalcisomes of Trypanosoma cruzi. Biochem. J. 1995, 310, 1005-1012. [CrossRef] [PubMed]

34. Moore, C.L. Specific inhibition of mitochondrial $\mathrm{Ca}^{++}$transport by ruthenium red. Biochem. Biophys. Res. Commun. 1971, 42, 298-305. [CrossRef]

35. Chamberlain, B.K.; Volpe, P.; Fleischer, S. Inhibition of calcium-induced calcium release from purified cardiac sarcoplasmic reticulum vesicles. J. Biol. Chem. 1984, 259, 7547-7553. [PubMed]

36. Novorolsky, R.J.; Nichols, M.; Kim, J.S.; Pavlov, E.V.; Woods, J.W.; Wilson, J.J.; Robertson, G.S. The cell-permeable mitochondrial calcium uniporter inhibitor Ru265 preserves cortical neuron respiration after lethal oxygen glucose deprivation and reduces hypoxic/ischemic brain injury. J. Cereb. Blood Flow Metab. 2020, 40, 1172-1181. [CrossRef]

37. Franco da Silveira, J.; Colli, W. Chemical composition of the plasma membrane from epimastigote forms of Trypanosoma cruzi. Biochim. Biophys. Acta 1981, 644, 341-350. [CrossRef]

38. Rodrigues, C.O.; Catisti, R.; Uyemura, S.A.; Vercesi, A.E.; Lira, R.; Rodriguez, C.; Urbina, J.A.; Docampo, R. The sterol composition of Trypanosoma cruzi changes after growth in different culture media and results in different sensitivity to digitonin-permeabilization. J. Eukaryot. Microbiol. 2001, 48, 588-594. [CrossRef]

39. Bone, G.J.; Steinert, M. Isotopes incorporated in the nucleic acids of Trypanosoma mega. Nature 1956, 178, 308-309. [CrossRef]

40. Schmatz, D.M.; Murray, P.K. Cultivation of Trypanosoma cruzi in irradiated muscle cells: Improved synchronization and enhanced trypomastigote production. Parasitology 1982, 85, 115-125. [CrossRef]

41. Chweih, H.; Castilho, R.F.; Figueira, T.R. Tissue and sex specificities in $\mathrm{Ca}^{2+}$ handling by isolated mitochondria in conditions avoiding the permeability transition. Exp. Physiol. 2015, 100, 1073-1092. [CrossRef]

Publisher's Note: MDPI stays neutral with regard to jurisdictional claims in published maps and institutional affiliations. 